Invited paper

\title{
Marie Curie's contribution to Medical Physics
}

\author{
Rosenwald Jean-Claude ${ }^{\mathrm{a}, *}$, Fridtjof Nüsslin ${ }^{\mathrm{b}}$ \\ ${ }^{a}$ Medical Physics Department, Institut Curie, 26, rue d'Ulm, 75005 Paris, France \\ ${ }^{\mathrm{b}}$ International Organization for Medical Physics, Technische Universität München, Germany
}

\begin{abstract}
A B S T R A C T
On occasion of its 50th anniversary, the International Organization for Medical Physics (IOMP) from now on is going to celebrate annually an International Day of Medical Physics for which the 7th November, the birthday of Marie Sklodowska Curie, a most exceptional character in science at all and a pioneer of medical physics, has been chosen. This article briefly outlines her outstanding personality, sketches her fundamental discovery of radioactivity and emphasizes the impact of her various achievements on the development of medical physics at large.
\end{abstract}

(c) 2013 Published by Elsevier Ltd on behalf of Associazione Italiana di Fisica Medica.

\section{Introduction}

The birth anniversary of Marie Curie, has been chosen by IOMP to celebrate from 2013 the International Day of Medical Physics. This paper is intended to cover the main aspects of her contribution to today's medical physics.

Marie Curie's life is well known and has been the subject of numerous articles, books, movies, shows, cartoons, etc. Born in Poland on November 7th 1867, Maria Sklodowska arrived in Paris in 1891 to study physics at the Sorbonne. In 1895, she married the physicist Pierre Curie specialized in crystallography and discoverer of the piezoelectric effect. After the discovery of radium in 1898, she was awarded in 1903 the Nobel Prize in physics jointly with her husband and the physicist Henri Becquerel. She became in 1908 the first woman with a professorship position at the Science University of Paris, and in 1911 she solely received the Nobel Prize in chemistry. She died in 1934, the very year of the discovery of the artificial radioactivity by her daughter and son in law, Irène and Frédéric Joliot-Curie.

However, this "success story" does not clearly point to the important role of Marie Curie's work, and beyond her work, to the influence of Marie Curie's personality on the earlier developments of what is today called "medical physics". Several characteristics might be pointed up throughout several periods of her life from the radium discovery in 1898 to the impressive growth and systematization of medical applications of radioactivity and X-rays between 1900 and 1934.

\footnotetext{
* Corresponding author. Tel.: +33 1443244 90; fax: +33144324509.

E-mail address: jean-claude.rosenwald@curie.net (R. Jean-Claude).
}

\section{Marie Curie's personality}

According to some science historians, Marie Curie played a decisive role, together with her husband, in the discovery of polonium and radium but was not any longer innovative or productive after the intensive period 1898-1903 and particularly after the accidental death of Pierre Curie in 1906. This erroneous vision might be due to Marie Curie's pragmatic personality and individual choices. Although she had an outstanding scientific level and was a strong advocate of pure science, she seemed more attracted by the applications of sciences than by its fundamental aspects. Actually, her practical skill and her persistency were individual traits that explained not only the initial discovery, but also the development of the radium industry leading to a large dissemination of medical applications, all these being constrained within a rigorous framework of standardization.

\section{The discovery}

In February 1896, 3 months after the discovery of X-rays by Wilhelm Conrad Röntgen, a strange phenomenon was observed by chance by Henri Becquerel: uranium salt was emitting invisible rays in the absence of any luminous excitation. He attributed this phenomenon to long-standing invisible phosphorescence and studied extensively in the following months the properties of these "uranic rays". At that time this discovery did not raise as much interest as the X-rays and Becquerel himself stopped pursuing his investigations. In December 1897, Marie Curie selected the uranic rays as main subject for her physics doctorate. 


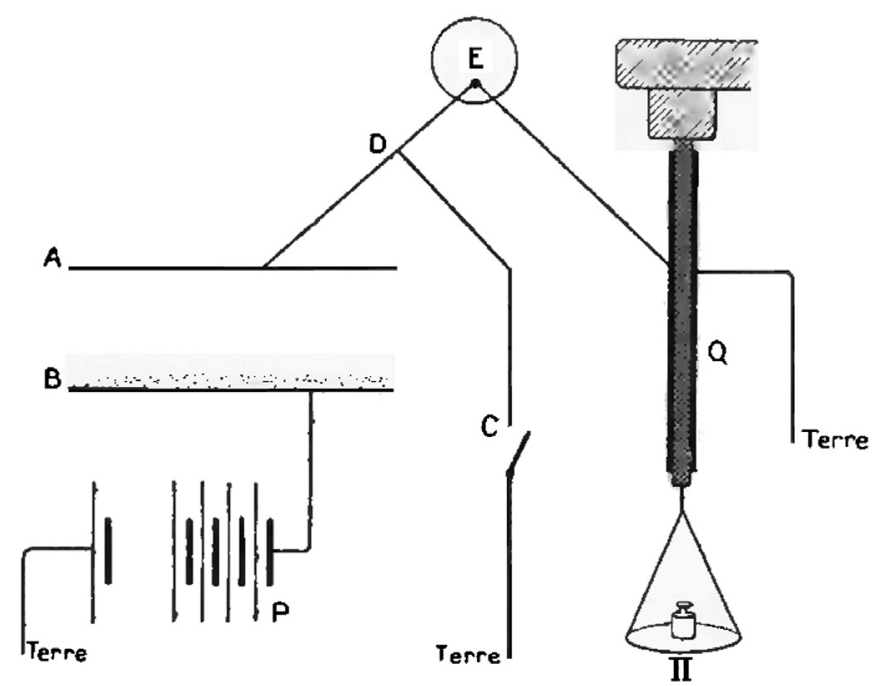

Figure 1. Schematic drawing of the device used in 1898 by Marie Curie to measure the radioactivity of various compounds: the radioactive material is pulverized on plate $B$ of the capacitor $\mathrm{A}-\mathrm{B}$. The air between $\mathrm{A}$ and $\mathrm{B}$ becomes conducting and the current measured by the electrometer $\mathrm{E}$ is exactly compensated by the known current generated from the piezo-electrical quartz $\mathrm{Q}$ while it is elongated during a given time by a given weight $\prod$. The time required to elongate $Q$ with mass $\prod$ while keeping the electrometer deviation steady is directly related to the radioactivity deposited on B (taken from M. Curie PhD thesis, 2nd edition 1904).

The main steps of her research might be retrieved from her laboratory logbooks: "les carnets de la découverte", ${ }^{1}$ but the notes are rather scarce and it is necessary to combine several sources to understand all details. Actually the first two months were dedicated to the design and practice of the experimental set-up consisting of a quadrant electrometer connected simultaneously to a rather primitive ionization chamber where the sample was deposited, and to a piezoelectric crystal elongated by a given weight (see Fig. 1). The apparatus and "savoir-faire" of Marie Curie warranted the high reproducibility that was required to quantify precisely the emission of various elements and compounds. She undertook this systematic investigation and in February 1898, only 2.5 months after the start of her research, she was convinced that the quantity of emitted rays was directly related to the quantity and atomic property of the element (i.e. uranium or thorium) independently of its chemical form, and she had found that some substances (particularly pitchblende, an uranium oxide ore) were far more radioactive that what was expected from their uranium content. She interpreted this strange behaviour as due to an unknown radioactive element, present in so small quantities that it escaped the previous chemical analyses [1]. To prove that hypothesis, she was challenged to isolate this element in a form as pure as possible, aiming at the determination of both its spectrum and atomic weight.

Convinced of the interest of this work, Pierre Curie decided in March 1898 to help his wife. After completing a partial chemical separation, they established the existence of a new element present in pitchblende. In July, in the publication of their results [2], they introduced the term "radio-activity" and suggested to name the new element "polonium". Resuming their work three months later, they finally discovered, from further chemical separation, that pitchblende contained another radioactive element and they named it "radium" [3]. At this stage of separation, the radium was
900 times more active than uranium, but a much larger quantity of ore was required to obtain a significant quantity of radium. Therefore the process had to be continued at a much larger industrial scale.

\section{The radium industry}

During the year 1899 more than 1 ton of ore residue obtained from an Austrian mine, was processed in cooperation with a factory specialized in physics and chemistry equipment. ${ }^{2}$ This cooperation offered the Curies an opportunity to continue their research. Pierre investigated radium properties while Marie's work was fully dedicated to the purification process aiming at the determination of the radium atomic weight, a systematic task where her tenacity was a very appreciable quality. In 1902 she reached her objective and estimated that the radium atomic weight was $225 \pm 1^{3}$ [4]. In June 1903, she defended her PhD thesis; she had obtained $1 \mathrm{~g}$ of radium from 2.8 tons of uranium but the radium was 1.4 million times more active.

The physiological characteristics of the radium rays were identified in 1900 [5] and radium medical application started in 1901 with an attempt to heal lupus scars [6]. With the general growth of the medical and scientific interest, enhanced by the attribution of the Nobel Prize in 1903, Pierre and Marie Curie had to respond to a strong demand for radium supply from the worldwide medical and scientific community. They favoured scientific exchanges and did not try to protect the process of radium production with a patent, because they believed that the scientific progress should benefit freely to humanity, and perhaps also because at the beginning they were not sure that there will be many practical applications.

However, radium was progressively becoming a "magic" substance, used in many instances such as medicine, agriculture or even leisure due to its luminescent properties; it was becoming a product deserving financial investment. After 1903, a new company, completely devoted to radium production, research and distribution, was founded in France by Emile Armet de Lisle. In spite of the absence of patent it was of mutual benefit for him to pursue the cooperation with the Curie laboratory. After the death of Pierre Curie in 1906, as the radium industry expanded worldwide, Marie Curie remained always anxious to establish good contact and fruitful collaboration between the industrial world and her own laboratory.

\section{Physics laboratories, metrology and medicine}

The radium discovery took place in a "shed" allocated by the Ecole Supérieure de Physique et de Chimie Industrielle de la Ville de Paris. In 1904, after Pierre and Marie Curie were awarded the Nobel Prize, the University allocated them a laboratory in the rue Cuvier. It was directed by Pierre Curie until his death, and by Marie Curie from 1906 to 1912. Marie Curie's research was dedicated to radioactivity. In total, this laboratory published 179 papers, including a fundamental treatise on radioactivity [7].

At that time there was an increasing need for scientific, industrial and medical use of radium to establish a metrological reference. During the International Congress of Radiology and Electricity that took place in Brussels in September 1910, the "curie"4 was adopted as unit of measurement of radioactivity. It was defined as 'the quantity of emanation in equilibrium with $1 \mathrm{~g}$ of radium'. This was

\footnotetext{
2 The "Société Centrale des Produits Chimiques" (SCPC).

${ }^{3}$ This result is consistent with the today's admitted value of 226 .

${ }^{4}$ In memory of Pierre Curie.
} 
a considerable amount of activity ${ }^{5}$ and this choice was the result of Marie Curie's insistence that the name of Curie was not associated to an infinitesimal quantity. The committee also assigned to Marie Curie the preparation of a radium international primary standard, a task that was completed in 1912 [8]. Several secondary standards were then prepared in various countries and several international intercomparisons were performed under strict conditions. In addition, at the end of 1911, Marie Curie installed in her own laboratory in the rue Cuvier, an accredited commercial service for radium calibration. It is worthwhile to note that, one year later, she was accused of conflict of interest with industry, and that it took more than one year before she could resume this activity; the condition was that a strict control would be exercised by University, including fixing prices for calibration services and sharing benefits.

In December 1909 the Dean of the University of Paris and the Director of the Pasteur Institute decided jointly to found the "Institut du Radium". This decision was the result of the extraordinary success of radiumtherapy for cancer cure combined with the notoriety and insistence of Marie Curie to have an independent laboratory to develop the study of radioactivity and its applications. Construction took place between 1911 and 1914, not far from the initial laboratory where radium was discovered. It consisted of 2 buildings separated by a small garden: Pavillon Curie dedicated to Physics and Chemistry (including calibration services) and Pavillon Pasteur dedicated to medical and biological applications. However, it was not before 1919, after the end of the World War I, that this Institute became operational.

During the war, Marie Curie was not inactive. She managed to raise funds to create about 200 fixed radiological installation and to equip 18 cars with X-rays (the so-called "petites Curies") in order to offer radiological service close to the battle fields. She was currently seen transporting spare parts and fixing equipment failures and she played an important role in teaching nurses with technical aspects of radiology.

After the war, as director of the physics laboratory of Institut du Radium, Marie Curie encouraged research and recruited students from many countries. She established a fruitful collaboration with Claudius Regaud, who was in charge of biological and medical applications. They joined their efforts to raise funds and create in 1921 the first clinic dedicated to radiumtherapy [9], devising an organizational scheme that has been continued over the years. ${ }^{6}$ Marie Curie travelled to USA in 1921 where she met President Harding and was gifted $1 \mathrm{~g}$ of radium. During a second visit in 1929 she received another time $1 \mathrm{~g}$ of radium that was dedicated to the medical applications performed in Poland. In 1932, two years before her death, she brought this radium to the newly created Warsaw Radium Institute and in her speech, she insisted on the fact that "Therapy should be permanently backed up by scientific research without which no progress is possible".

\section{Conclusions}

This article illustrates the Marie Curie's vision of the added value of the scientific research to the medical field. It makes sense for a medical physicist who, by essence, takes advantage of its expertise in physics sciences to ensure and improve quality and safety of medical care. In this respect, Marie Curie's career is exemplary since she proved that:

1. A quantitative rigorous and systematic approach can lead to a discovery of the utmost importance.

2. Open international cooperation favours science development and its applications.

3. Partnership of science and industry is invaluable to advance application of research in practice.

4. Medical use of radiation should be founded on sound physics and should be referred to a structured metrological framework.

With regard to our medical physics profession we may ultimately learn from the biography of Marie Curie: No scientific progress without research.

\section{Acknowledgements}

This paper has been mainly inspired by two books: "Marie Curie et son laboratoire" from Soraya Boudia [10] and "Radium history mosaic" from Richard Mould [11].

The assistance from Renaud Huynh and Natalie Pigeard from the Musée Curie is highly appreciated.

\section{References}

[1] Curie M. Rayons émis par les composés de l'uranium et du thorium. Comptes rendus de l'Académie des Sciences 1898;126:1101-3.

[2] Curie P, Curie M. Sur une substance nouvelle radio-active contenue dans la pechblende. Comptes rendus de l'Académie des Sciences 1898;127:1101-3.

[3] Curie P, Curie M, Bémont G. Sur une nouvelle substance fortement radioactive contenue dans la pechblende. Comptes rendus de l'Académie des Sciences 1898; $127: 1215-7$.

[4] Curie M. Sur le poids atomique du radium. Comptes rendus de l'Académie des Sciences 1902;135:161-3.

[5] Walkhoff FO. Unsichtbare, photographisch wirksame Strahlen. Photographische Rundschau 1900;28:189-91.

[6] Danlos H, Bloch P. Note sur le traitement du lupus érythémateux par des applications du radium. Annals Dermatolog et Syphilolog 1901;2:986-8.

[7] Curie M. Traité de radioactivité. Paris: Gauthier-Villars; 1910.

[8] Curie M. Les measures en radioactivité et l'étalon du radium. Journal de Physique 1912;2:795-826.

[9] Curie M, Regaud C. Pour le dévelopement de l'Institut du Radium de Paris et pour l'avenir de la radiumthérapie en France. Paris: Institut du Radium; 1920.

[10] Boudia S. Marie Curie et son laboratoire. Edition des Archives Contemporaines; 2001.

[11] Mould R. Radium history mosaic. Nowotwory Journal of Oncology 2007 [Supplement].

\footnotetext{
5 In 1910 , the total worldwide radium quantity was of the order of $10 \mathrm{~g}$.

6 The present Institut Curie is a large multisite complex dedicated to cancer care, research and teaching. The two original "Pavillons" still exist and are allotted to research; in addition, the Curie Pavillon hosts a museum recently renewed. The Paris hospital, named after Claudius Regaud, consists of several buildings constructed partly on the ground of the original radiumtherapy clinic.
} 